\title{
Introduction of Weight-In-Motion Control System as the component of the "smart" transport infrastructure
}

\author{
Elena Vasilyeva* \\ Moscow State University of Civil Engineering, Yaroslavskoe shosse, 26, Moscow, 129337, Russia
}

\begin{abstract}
The purpose of the research is to estimate the opportunities of such "smart" technology as the automated systems of Wight-in-Motion control (weight-and-dimensional control in the highways), to promote the improvement of the situation with the freight transportation by motor transport. The methods of weight-and-dimensional monitoring are considered. Advantages and disadvantages of the automated system in comparison with the traditional one are revealed. The conclusion is drawn on the cost recovery and financial expediency of the projects of introduction of Wight-in-Motion control systems. Obtaining such economic, ecological and social results as the reduction of cases of excesses of admissible mass of freight, perfecting the logistic activity in our country, collecting additional income for the regional budget, the decrease in the destroying impact on highways, the decrease in the expenses on their repair as well as providing sources for financing of such repair, the decrease in ecological harm from driving of overweighted vehicles, the increase in traffic safety, the reduction of quantity of accidents and life losses, caused by driving of the overweighted vehicles are proved.
\end{abstract}

\section{Introduction}

The introduction of weight-and-dimensional monitoring is caused by several factors, such as safety, preservation of infrastructure and reduction of emissions of pollutants in the atmosphere, decrease in the destroying influence on the road coverings $[1,2]$ which increase with growth in weight of heavy-loaded transport exponentially. The application of such systems is also caused by the need to keep the "harmonious" competition for the allocation of the market of transport-and-logistic services among different types of transport; and that is especially relevant in Russia [3, 4]

The systems of weight-and-dimensional monitoring, falling into projects of telematics (the industry, which is new for Russia) are meant to contribute to the solution of this problem.

According to the Department of state policy in the field of road economy of the Ministry of Transport of the Russian Federation, more than one third of all the trucks and

\footnotetext{
* Corresponding author: elena.chibisova_metr@mail.ru
} 
road trains violate the Rules of transportation of freight by the motor transport, from them more than $50 \%$ move with violation of weight parameters on the mass of the vehicle and (or) on the load of an axis, thus doing harm to the highway [5].

The problem of weight-and-dimensions control of motor transport is quite relevant. The overweight of the vehicle, which breaks the rules of transportation of freight by automobile transport, exceeds $40 \%$ of the admissible weight and (or) loads of an axis.

It should be noted, that according to the American Association of State Highway and Transportation Officials (AASHTO), a journey of 1 truck, weighing 20 tons is equal to a journey of 20,000 cars according to the harm done [6].

\section{Materials and Methods}

In some European countries, as well as in Russia, weight-and-dimensional control on highways is carried out in two stages. At the first stage potential violators are identified during driving on all the strips of the road without slowing down of the traffic flow. At the second stage observed datas are transferred to the systems of stationary monitoring of weight-and-dimensions control of the vehicle, located in $1 \ldots 10$ and even more kilometers from the location of the "dynamic weights" [7, 8].

Initial identification of the violator can be carried out by traditional methods (visually) or can be automated.

So, in Russia in case of traditional method either eyes help the traffic police officer to get out the vehicles of the violator from the stream (the car is weighted "up to the boards", it is going more slowly, than it could, it has more than five axes, etc.), or the measuring apparatuses (special framework established on the road) allow to do that. Such frameworks measured weight and dimensions of the vehicle and, having found a violator, who was breaking the rules, warned about it a post of traffic police, which was down the road. The information, obtained thanks to such measuring apparatuses had exclusively preventive character and had no power for discharging of penalties. It just specified, who needs to be stopped and whose documents with dimensions need more careful check.

Besides the stationary posts of weight-and-dimensional control mobile posts operate on the roads of Russia. They represent the underlayed axial scales, which are included in the package of the special certified vehicle which makes these posts mobile. Posts can ply on various roads. The platforms, where mobile scales are set, have to be certified, because the precise measurement of the vehicle requires, at least, the flat road.

Nobody has cancelled such a form of weight-and-dimensional control, it still works. However, now more advanced, automated systems known in the world as Weigh-In-Motion (WIM) systems were added to such posts. And if it is necessary for the first method that the car should reduce its speed, then the second method, WIM, is able to receive all the necessary parameters when the heavy truck moves with the speed more than $100 \mathrm{~km} / \mathrm{h}$. The WIM system allows to define dimensions, mass of the vehicle, weight on each axis, taking into account its parameters. Actually the vehicle's 3D model is made without the need to stop or reduce the speed. The WIM system realizes the principle of work, which cornerstone is the algorithm of creation of 3-dimensional model and restitution of spatial structure of the object with the use of the modern methods on the basis of the technologies of machine vision, based on high-speed measurement of profiles of the moving vehicles in various sections synchronously with the measurement of the instantaneous speed of the vehicle for each section. [9, 10, 11, 12, 13].

Creation of the profile is made by the method of the laser triangulation by the means of triangulable measuring instruments of the profile, and the measurement of the instantaneous speed is made by the means of the optical meter of the cross speed. 
According to the specifications the system of weight-and-dimensional control includes: the system of weight control, the system of dimensional control and the system of video surveillance and video fixing.

The system components include:

- Strain gauges - for the determination of weight parameters of the vehicle without reduction in the speed of driving,

- Laser 3D sensors - for the definition of the vehicle dimensions,

- Cameras for photo- and video- fixing - for obtaining images of the vehicle and a discernment of license plates,

- Computing inventory (protected controller) - for the control of the peripheral equipment,

- Communication inventory - for data transmission through $3 \mathrm{G}$, fiber-optic channel or satellite communication, for enciphering of data,

- Inductive sensors - for the definition of the fact of the vehicle driving and the wheel formula and also for the definition of the vehicle speed,

The general scheme of the units placement on the site is presented in Figure 1.

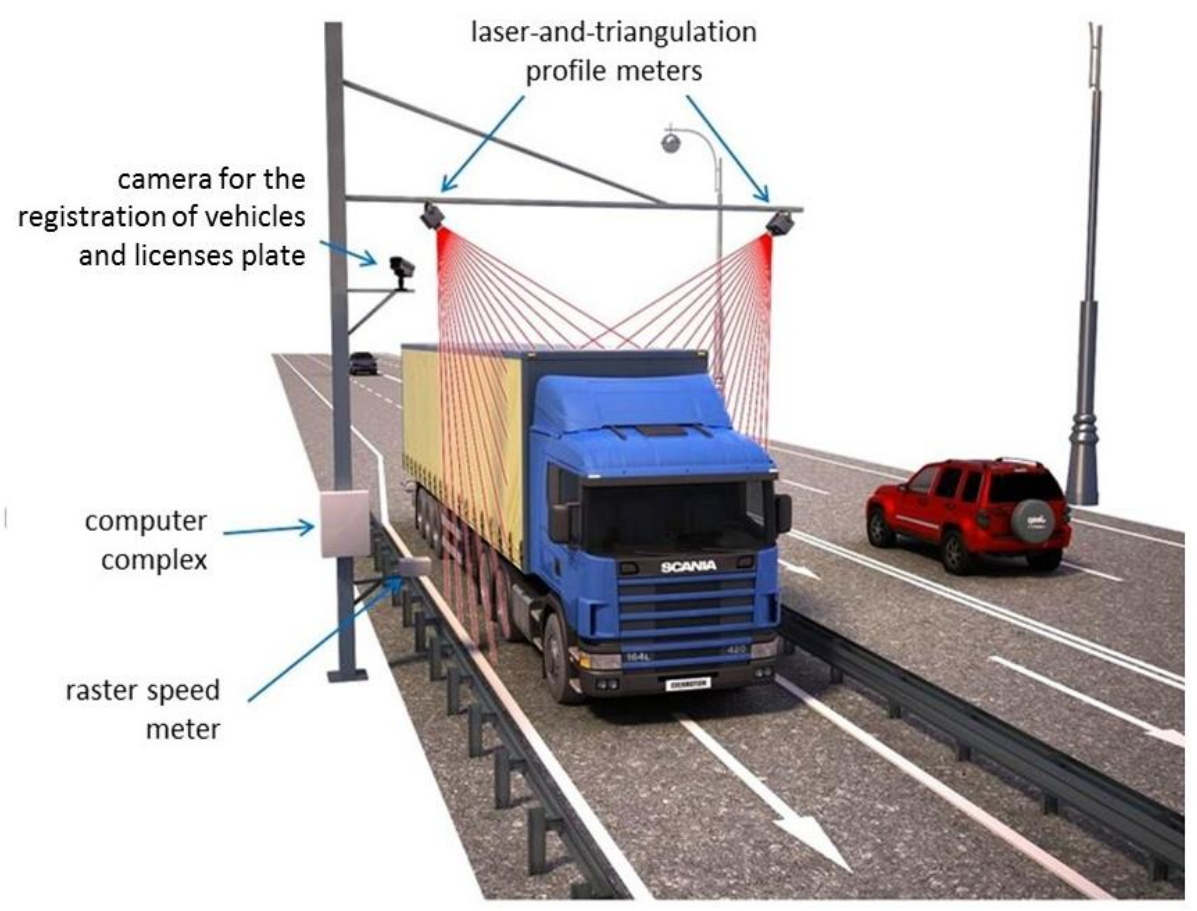

Fig. 1. General scheme of placement of the WIM system units (drawn by the author on the basis of schemes from GirWIM.com [8])

After defining the parameters of the vehicle, the data are transferred not to a post of the traffic police, but to the uniform information centre, where the vehicle is identified, its owner is identified, the availability of permission is checked, and in the absence of the permission the protocol on violation is formed and the penalty is exposed without participation of the human (Figure 2, ). 


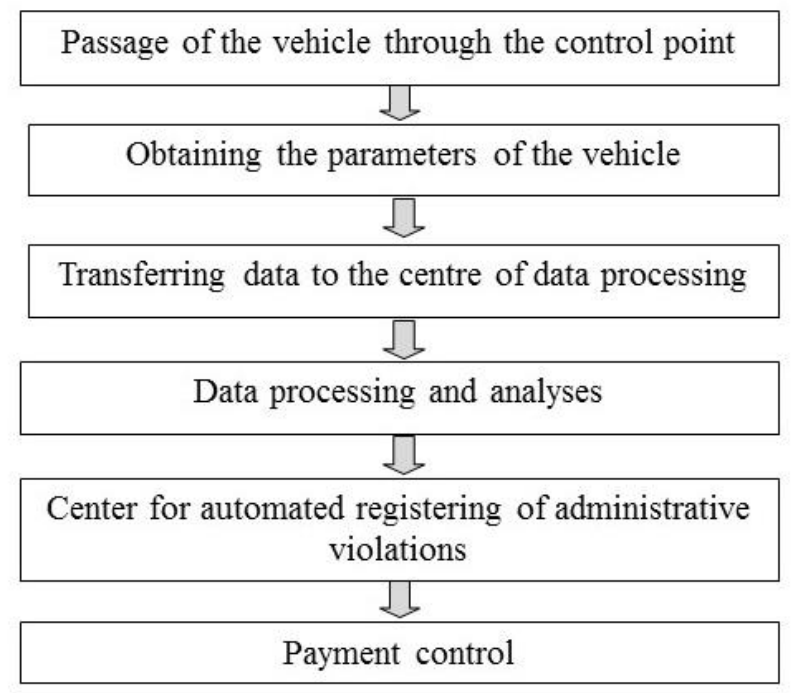

Fig. 2. Procedure for the violator of the rules of the freight transportation (drawn by the author)

The arrangement of the control inventory is made on U-shaped (console) or on Lshaped supporting structure, supporting structure.

The interface of interaction and data exchange of the control complex provides a high level of data protection from any unauthorized access and change with the differentiation of the configured access rights for various groups of users.

The next stage in the development of methods weight-and-dimensional control is WIM FO (Fiber Optic). This system is based on the use not photo- and video fixing, but several sensors in the paving, connected with hardware and software.

And the most perspective method is the use of onboard control systems of weighing, which allow to carry out control when loading, unloading and throughout all the route of traffic, thanks to immediate installation onboard ("scales always with you" system) seem today.

Since 2014 in the world there have been about 15 large producers of WIM equipment: CAMEA, Captels, Cestel, Cross Zlin, ECM, Haenni, Intercomp, IRD, Kalibra, Kistler, MSI, SF Dynamics, Sterela, TDC and TDS [14]. In Russia in 2014 RT-Invest Transport Systems Company acquired the right to create a system of collection of payments for freight PLATON ("PLAta za TONny", that is Russan for "payment per one ton"). It is also necessary to mention the IBS company, the developer of the "Monitoring of Traffic Flow on Federal Points of Weight Monitoring" system. Nevertheless, the projects of telematics, the automated systems of photo- and video- fixing and monitoring is a new industry in Russia.

Nowadays the roads in more than 17 regions of Russia are equipped with "smart scales". In 2018 the quantity of the automated points of weight-and-dimensional control reached 125, in 2020 there expected to be 387 of them. They will capture all the federal highways at the rate on each 100-150 kilometers. Then the automated control, most likely, will begin to extend to the regional roads too.

\section{Results}

The figures, presented in Table 1 [15]. 
Table 1. Share of violations and average overweight for the categories of vehicles in 2018

\begin{tabular}{|c|c|c|c|c|c|}
\hline $\begin{array}{c}\text { Category } \\
\text { of the } \\
\text { vehicle }\end{array}$ & $\begin{array}{c}\text { Name of the vehicle } \\
\text { category }\end{array}$ & $\begin{array}{c}\text { Quantity } \\
\text { of } \\
\text { violations, } \\
\text { total }\end{array}$ & $\begin{array}{c}\text { Share of } \\
\text { violations, } \\
\% \text { according } \\
\text { to } \\
\text { dimensions }\end{array}$ & $\begin{array}{c}\text { Share of } \\
\text { violations, } \% \\
\text { according to } \\
\text { weight } \\
\text { parameters }\end{array}$ & $\begin{array}{c}\text { average } \\
\text { overweight, } \\
\%\end{array}$ \\
\hline 3 & single three-axle truck & 14.75 & 2.68 & 12.30 & 37.08 \\
\hline 4 & single four-axle truck & 36.83 & 1.73 & 35.41 & 37.26 \\
\hline 6 & road trains, trailed, three- & 5.31 & 1.94 & 3.49 & 17.02 \\
\hline 7 & road trains, trailed, four-axle & 15.68 & 13.72 & 2.51 & 21.38 \\
\hline 8 & road trains, trailed, five-axle & 28.64 & 21.79 & 21.46 & 31.51 \\
\hline 9 & road trains, trailed, six-axle / & 32.40 & 12.47 & 21.46 & 31.51 \\
\hline \multicolumn{2}{|c|}{ Total in the Russian Federation } & 26.32 & 17.72 & 9.60 & 29.48 \\
\hline
\end{tabular}

Statistics proves that the number of violators after the automation (after the WIM systems introduction) decreases more than 100 times [16].

The WIM system:

- Provides automation of the public service of delivery of special permissions to automobile transportation of large-size and heavy freights across the regional highways and maintaining the uniform base of permissions in electronic form and also allows to carry out the interaction with the federal centre for the check of the given special permissions and coordination of drives along regional roads.

- Acts as the effective instrument of the identification and punishment of breakers of rules of transportations of large-size and/or heavy freights by the motor transport and also other violations: the high-speed mode, driving through a roadside, departure on the strip of oncoming traffic.

- Allows to save budgetary funds for the repair of highways due to the decrease of violators and harm to the highways.

- Ensures safety on the roads due to the coordination and monitoring of routes of transportation of large-size and heavy freights.

- Allows to create additional sources of revenues for the budget for financing of works on the highways maintenance [17].

The research, carried out by the author allows to to generalize advantages and advantages of stationary and mobile points of weight-and-dimensional control and the automated WIM control points in comparison (Table 2).

Table 2. Comparative characteristic of stationary and mobile points of WDC and WIM systems

\begin{tabular}{|c|c|c|}
\hline & Stationary and mobile points & WIM systems \\
\hline advantages & $\begin{array}{l}\text { 1) stop (stop moving) of the } \\
\text { violator's vehicle; } \\
\text { 2) possibility of calculating } \\
\text { of the damage, actually } \\
\text { caused }\end{array}$ & $\begin{array}{l}\text { 1) avoiding the human } \\
\text { factor ; } \\
\text { 2) working } 365 \text { days a } \\
\text { year in } 24 \times 7 \text { mode and } \\
\text { providing round-the- } \\
\text { clock control; } \\
\text { 3) inevitability of } \\
\text { punishment in case of }\end{array}$ \\
\hline
\end{tabular}




\begin{tabular}{|l|l|l|}
\hline & & $\begin{array}{l}\text { violations ; } \\
\text { equal control conditions } \\
\text { for all the road users }\end{array}$ \\
\hline disadvantages & 1) $\begin{array}{l}\text { insufficient number of } \\
\text { employees to organize } \\
\text { round-the-clock work of } \\
\text { posts ; }\end{array}$ & $\begin{array}{l}\text { 1) } \begin{array}{l}\text { not 100th vehicle } \\
\text { control coverage ; } \\
\text { 2) } \\
\text { the violator's vehicle is } \\
\text { not stopped }\end{array} \\
\text { 2) } \begin{array}{l}\text { control ; } \\
\text { not 100\% vehicle control } \\
\text { coverage }\end{array}\end{array}$ \\
\hline
\end{tabular}

The analysis of the expected results from introduction of WIM proves that the project will pay off at the expense of:

- the economy of budget funds on the maintenance of regional highways, since the damage to the highways, caused by those, who break the rules of transportation of freight decreases;

- collecting penalties from the violators of transportation of freight and violators of the speed mode;

- payments, made by the users of highways for permissions to transportation.

But the main result of introduction of the WIM system is not monetary. The analysis of the situation in the regions proved that in the first weeks of operation the quantity of the overweighted transport on the corresponding sections of the roads decreased at least three times. This is the very result, which was desirable upon the introduction of the WIM systems. Penalties are only the instrument of upbringing of the domestic carriers at the initial stage of the programme of automatic control. The final purpose is ensuring safety on the roads.

\section{Discussion}

However, the projects of WIM control meet their critics.

First of all, the accuracy of measurements is called into question. When automatic weighing is used just to snatch out the possible violator from the stream, its results are rechecked on stationary (fixed) scales (i.e. the work is performed in 2 steps), but the new "smart" system does not give the transporter such a chance.

Statistics proves that the probability of the correct assessment if speed makes up to 130 $\mathrm{km} / \mathrm{h}$ is $95 \%$ [18]. According to the members of the International community of the WIM systems, historically the insufficient accuracy of the measurements performed by the means of the systems of dynamic weight-and-dimensional monitoring was considered as the main obstacle to the use of these systems in many countries by the analogy with the systems of automatic control of the high-speed mode with the corresponding imposing of administrative responsibility. Representatives of the International community of the WIM systems from the Czech Republic report that lawyers appeal against proofs of the violations, received by the WIM system, in court. Therefore, it is considered that it is better bring to justice only the vehicles with considerable overweight [19].

In fact, registered overweight can not depend on the evil will of transporter in any way but be simply an accident consequence.

For example, after driving around the poor, destroyed roads, fastening of freight weakens. As a result, freight is displaced and the load of one of the axes increases. Any driver, knowing, that his car has discrepancy on axes, and having found a special platform with fixed scales near the control point, where it would be possible to check the results of 
measurements and if it is possible, to eliminate the violation, would not go with overload further, continuing to do harm to roads without any permission and malicious intent [20].

Even more problems are connected with bulk freights: when driving the barycentre is displaced and weighing shows a surplus load on an axis. But if to place the same vehicle on fixed scales, to give liquids time to calm down, then any overload would not be "recorded". For such cases transporters suggest either to cancel weighing of the trucks, transporting bulk freights, referring to the experience of the European countries, or to increase the admissible error of measurement for them [21].

The aforesaid controversial matters and disadvantages are peculiar to traditional WIM systems to a large extent; they are being solved by the newest WIM systems with the use of fiber-optic sensors and by the onboard control systems of weighting as well. Anyway, technical improvement of weight-and-dimensional control is required still.

\section{Conclusions}

The positive effects from the introduction of WIM systems include the following:

1. The decrease in the quantity of violators allows to reduce the damage to highways and, as a result, to save budgetary funds for repair of public highways.

2. The increase in the receipts of money for the regional budget from the collected penalties for violations of the rules of transportation of freight and indemnification of the harm, caused to highways by overweighted vehicles. Besides, payments for the special permissions come to the budget of the region.

3. Ensuring the inevitability of punishment for non-compliance with the special traffic regulation of heavy and large-size vehicles.

4. The decrease in the quantity of violators (and those are generally the vehicles which driving overweighted) allows to increase the traffic safety considerably.

5. But the main possible result of the project is the social-and-economic effect, expressed in saving the human lives. This effect is reached thanks to strengthening of the measures for traffic safety, the use of innovative technologies and control algorithms of the intellectual transport systems.

At the same time the problem of the problem of insufficient accuracy of measurements or administrative mistakes exists; it can be solved by further technical progress, improvement of the organization of monitoring and rational approach to punishment of violators, development of the economic and legal relations among the participants of transportation activity.

According to the carried-out analysis, it is possible to conclude that the application of the WIM control systems, which are still characterized by the insufficient level of accuracy of measurements, so far demands so-called "political will" as well as cooperation "from below-up" and "from top to down". In general, promoting of reports on technical, legal, economic aspects of the existing practice of the development of the WIM systems, creates the prerequisites for better understanding of economic-and-ecological advantages, which can be brought to the society and to the transport sphere by these systems.

\section{References}

1. J. Carson, T. Kearney, Public Roads, 72 (6) (2009)

2. D. Labry, V. Dolcemascolo and B. Jacob, Proceedings 8th International Symposium on Heavy Vehicle Weights and Dimensions. Loads, Roads and the Information Highwayí, Johannesburg, South Africa, 8, (2012)

3. A. Mottaeva and E. Vasilyeva, MATEC Web of Conferences, 239, 04019 (2018) 
4. Y. M. Mohammed, N. Uddin, Transportation Management, 1 (2018) doi:10.24294/tm.v1i2.701

5. E. Vasilyeva, I. Polyakova, Krasnoyarie science, 6 (3-2), 130-134 (2017)

6. AASHTO, National Academies Report Outlines FHWA Research Path for Revising Truck Size/Weight Limits, [Digital resource]. Access mode: https://aashtojournal.org/2018/11/30/national-academies-report-outlines-fhwaresearch-path-for-revising-truck-size-weight-limits/

7. Technology-revo.blogspot.ru Technology revolution [Digital resource]. Access mode: http://technology-revo.blogspot.ru/2015/12/weigh-in-motion-axle-scales.html

8. GirWIM.com. High speed WIM solution [Digital resource]. Access mode: http://girWIM.com/high-speed-WIM-solution/

9. Is-WIM.org. The international society for Weigh in Motion [Digital resource]. Access mode: http://www.is-WIM.org/index.php?nm=0\&nsm=2\&lg=en

10. N. Todorovic, M. Subotić, TEHNIKA-SAOBRAĆAJ, 61, 661-675 (2014)

11. Zhang Lixin, An evaluation of the Technical and Economic Performance of Weigh-InMotion Sensing Technology, Master thesis (University of Waterloo, Ontario, Canada, 2007)

12. A. Regan, et al., Strategies for Successful Implementation of Virtual Weigh and Compliance Systems in California (University of California, Berkeley, 2006)

13. Yarah Basyoni, Moustafa S Aly, Hatem Abdel-Latif, Role of Engineering Towards A Better Environment 9th International Conference - RETBE'12 (2012) Access Mode: https://www.researchgate.net/publication/274832014_An_Economic_Feasibility_Asses sment_for_Applying_Weigh_in_Motion_WIM_Systems_in_Egypt

14. A. Ageev, V. Vdovin, V. Nazarov, S. Pavlov, Roads of Eurasia, 5, 28-33 (2013)

15. I. Polyakova, E. Chibisova, Economy and entrepreneurship, № 4-1 (69-1), 816-819 (2016)

16. E. Vasilyeva, Economy and entrepreneurship, 5 (94), 271-274 (2018)

17. N. Verstina, T. Tereshkina, M. Treyman, MATEC Web of Conferences, 251, 05027 (2018)

18. A.V. Tereshkin, Economic-and-administrative technologies of the 21 st century: theory and practice, training of specialists: materials of the scientific-and-practical conference, 86-89 (2018)

19. Centre of monitoring of the safe operation of highways of Federal Highway Agency. On importance of athe system of weight and dimensional monitoring. Access Mode: http://gucmp.ru/index.php/infomratsiya-fku-rosdormonitoring/499-o-vazhnostisistemy-vesogabaritnogo-kontrolya

20. Report "Technology of the smart cities" (St. Petersburg, 2017)

21. Intellectual cities. Smart cities [Digital resource] Access mode: http://www.tadviser.ru/index.php 